\title{
Maverick total disc replacement in a real-world patient population: a prospective, multicentre, observational study
}

\author{
Richard Assaker ${ }^{1} \cdot$ Karsten Ritter-Lang $^{2} \cdot$ Dominique Vardon $^{3} \cdot$ Stéphane Litrico $^{4}$. \\ Stéphane Fuentes $^{5} \cdot$ Michael Putzier $^{6} \cdot$ Jörg Franke $^{7} \cdot$ Peter Jarzem $^{8}$. \\ Pierre Guigui ${ }^{9}$ - Gérard Nakach ${ }^{10} \cdot$ Jean-Charles Le Huec ${ }^{11}$
}

Received: 1 July 2014/Revised: 23 March 2015/Accepted: 26 March 2015/Published online: 7 June 2015

(C) Springer-Verlag Berlin Heidelberg 2015

\begin{abstract}
Purpose Controlled trials have shown that total disc replacement (TDR) can provide pain and disability relief to patients with degenerative disc disease; however, whether these outcomes can also be achieved for patients treated in normal surgical practice has not been well documented. Methods This prospective, international study observed changes in disability and back pain in 134 patients who were implanted with Maverick TDR within the framework of routine clinical practice and followed for 2 years postsurgery. Primary and secondary outcomes were the differences from baseline to 6 months post-surgery in the means of the Oswestry Disability Index and the change in back pain intensity assessed on a $10-\mathrm{cm}$ visual analogue
\end{abstract}

R. Assaker and K. Ritter-Lang were co-first authors.

Electronic supplementary material The online version of this article (doi:10.1007/s00586-015-3918-x) contains supplementary material, which is available to authorized users.

Richard Assaker

richardassaker@gmail.com

1 Service de Neurochirurgie, Centre Hospitalier Régional Universitaire, Hôpital Roger Salengro, 2 Avenue Oscar Lambret, 59037 Lille Cedex, France

2 Orthopaedium-potsdam, Karl-Liebknecht-Str. 21/22, 14482 Potsdam, Germany

3 Clinique du Cours Dillon, 45 Rue de Gironis, 31000 Toulouse, France

4 Service de Neurochirurgie, Hôpital Pasteur, Centre Hospitalier Universitaire de Nice, 30 Av. de la Voie Romaine, 06000 Nice, France

5 Service de Neurochirurgie, Hôpital de la Timone, 264 rue Saint Pierre, 13385 Marseille, France scale, respectively. Mean patient age at surgery was 43 years, but ranged up to 65 years.

Results One hundred twenty-three patients had an implant at one level, 10 patients at two levels, and one patient at three levels. Statistically significant improvements in mean disability $(-25.4)$ and low back pain intensity $(-4.0)$ scores were observed at 6 months postoperatively $(P<0.0001$ for both) in the hands of experienced surgeons $(>10$ TDRs per centre). During the study, 56 patients (42\%) experienced a complication or adverse event.

Conclusions This is the first international observational study to report outcomes of TDR in real-world clinical settings. We showed statistically significant improvements in disability and pain scores at 6 months following Maverick TDR, which were maintained for 2 years alongside an acceptable rate of perioperative complications. The safety and tolerability shown in this observational study were comparable to those from controlled trials.

6 Charité Berlin, Klinik für Orthopädie, Charitéplatz 1, 10117 Berlin, Germany

7 Department of Spinal Surgery, Klinikum Dortmund, Beurhausstr. 40, 44137 Dortmund, Germany

8 Montreal General Hospital, 1650 Cedar Avenue T8-200, Quebec H3G 1A4, Canada

9 Service de Chirurgie Orthopédique, AP-HP, Hôpital Beaujon, 100 Bd Général Leclerc, 92110 Clichy, France

10 Service de Chirurgie Orthopédique, Centre Hospitalier de Meulan, 1 rue Fort, 78250 Meulan, France

11 Hôpital Pellegrin, Centre Hospitalier Universitaire de Bordeaux, Place Amélie Raba Léon, 33000 Bordeaux, France 
Keywords Arthroplasty - Prospective study · Intervertebral disc degeneration · Lumbar vertebrae . Registry $\cdot$ Total disc replacement

\section{Introduction}

Since 50 years, a pathologic disc associated with lumbar degenerative disc disease (DDD) that did not respond to conservative care has been preferentially treated by spinal fusion. As an alternative, in 1984, lumbar spinal arthroplasty or disc replacement emerged [1-4]. Disc replacement can provide pain relief by resecting the diseased intervertebral disc and dynamically stabilising the segment, allowing restoration and maintenance of spine biomechanics. Compared to fusion, this is expected to reduce the incidence of adjacent segment degeneration [5-7].

The Maverick disc, a two-piece lumbar disc prosthesis, can be implanted at any spinal level from T12/L1 to L5/S1. It has a semi-constrained metal-on-metal design, preserving motion by a ball-and-socket construct with a physiological posterior centre of rotation [8]. A 2-year randomised controlled trial (RCT) demonstrated statistical superiority of Maverick over spinal fusion based on key clinical outcomes, including disability and pain [9].

The optimal patient population for total disc replacement (TDR) is not fully defined [9-11]. Available information outside a controlled clinical study setting comes from a single national registry $[10,12]$. The objective of this first international observational study was to investigate changes in disability and back pain in a broad patient population treated with Maverick TDR in varied surgical practices reflecting different national standards of care.

\section{Patients and methods}

\section{Study design and participants}

This prospective observational study of normal surgical practice for the MAV Motion Segment Replacement (MSR; A-MAV and O-MAV; Medtronic Sofamor Danek, Memphis, TN, USA) was conducted at 11 centres in France (7: Clinique de Neurochirurgie Hôpital Roger Salengro, Centre Hospitalier Universitair Pellegrin Tripode; Centre Hospitalier de Meulan, Service de Neurochirurgie Hôp Nice, AP-HP Hôpital Beaujon, Clinique du Cours Dillon, Centre Hospitalier La Timone), Germany (3: Universitätklinikum Magdeburg, Praxis für Orthopädie und Neurochirurgie Potsdam, Charité Berlin-Klinik für Orthopädie), and Canada (1: Montreal General Hospital) from February 2009 to July 2013. One hundred thirty-four patients with back pain were implanted with Maverick discs and followed for 2 years. Study centres were required to have at least $10 \mathrm{TDR}$ per year prior to participation. The study is registered at http://www.clinicaltrials.gov (NCT01338493).

Patients eligible for MAV MSR disc replacement according to the labelling were included at the discretion of the surgeon and managed in routine clinical practice. Patients were not excluded for having fusion-treated degenerative spondylolisthesis adjacent to the implantation level. Patients were enroled by signing informed consent and having their data entered in the electronic case report form (eCRF).

\section{Ethical considerations}

This study was conducted in agreement with the Declaration of Helsinki and local regulations of the participating countries. According to the requirements, a notification letter regarding the registry was sent to, or written approval was obtained from, the Ethics Committee (EC)/Institutional Review Board (IRB)/Human Research Ethics Committee (HREC) before the start of the study. Data were collected by web-based eCRF according to the legislation for each participating country. All enrolled patients gave written informed consent in their local language before participation.

\section{Study procedures}

Patients were treated by lumbar spinal arthroplasty. A complete anterior discectomy was performed followed by A-MAV (implant for anterior insertion at levels T12-S1, 126 implants) or O-MAV (implant for oblique insertion at levels L4-L5, 20 implants) insertion to replace the damaged lumbar intervertebral disc [8] at up to three levels; patients could also be treated with adjacent fusion. All procedures and assessments (Table 1) were part of the standard treatment a patient outside of the study would also receive.

\section{Outcome measures}

Primary outcome was change from baseline at 6 months post-surgery of mean Oswestry Disability Index (ODI version 2.1). Secondary outcome was change at 6 months versus baseline in back pain intensity assessed on a $10-\mathrm{cm}$ visual analogue scale [VAS; $0 \mathrm{~cm}$ (no pain) to $10 \mathrm{~cm}$ (worst possible pain)]. The percentage of patients attaining a $\geq 15$-point improvement in ODI-criterion for success defined by the US Food and Drug Administration (FDA) [9]—was calculated. 
Table 1 Summary of procedures and assessments

\begin{tabular}{|c|c|c|c|c|c|c|}
\hline & $\begin{array}{l}\text { Visit } 1 \\
\text { Pre- } \\
\text { operative }\end{array}$ & $\begin{array}{l}\text { Visit } 2 \\
\text { Day of } \\
\text { surgery }\end{array}$ & $\begin{array}{l}\text { Visit } 3 \\
\text { Day of } \\
\text { discharge }\end{array}$ & $\begin{array}{l}\text { Visit } 4 \\
6 \text { months } \\
( \pm 1 \text { month })\end{array}$ & $\begin{array}{l}\text { Visit } 5 \\
1 \text { year } \\
( \pm 2 \text { months })\end{array}$ & $\begin{array}{l}\text { Visit } 6 \\
2 \text { years } \\
( \pm 2 \text { months })\end{array}$ \\
\hline Data release form or informed consent & $\mathrm{x}$ & & & & & \\
\hline Indications/contraindications & $\mathrm{x}$ & & & & & \\
\hline Demographics & $\mathrm{x}$ & & & & & \\
\hline Medical history & $\mathrm{x}$ & & & & & \\
\hline $\begin{array}{l}\text { Pain medications and non-drug pain } \\
\text { treatments }\end{array}$ & $\mathrm{x}$ & & $\mathrm{x}$ & $\mathrm{x}$ & $\mathrm{x}$ & $\mathrm{x}$ \\
\hline Neurological examination & $\mathrm{x}$ & & $\mathrm{x}$ & $\mathrm{x}$ & $\mathrm{x}$ & $\mathrm{x}$ \\
\hline Patient questionnaires & $\mathrm{x}$ & & & $\mathrm{x}$ & $\mathrm{x}$ & $\mathrm{x}$ \\
\hline Working/activity status & $\mathrm{x}$ & & & $\mathrm{x}$ & $\mathrm{x}$ & $\mathrm{x}$ \\
\hline Neutral X-ray & $\mathrm{x}$ & & $\mathrm{x}$ & $\mathrm{x}$ & $\mathrm{x}$ & $\mathrm{x}$ \\
\hline Flexion/extension X-rays & $\mathrm{x}$ & & & $\mathrm{x}$ & $\mathrm{x}$ & $\mathrm{x}$ \\
\hline MRI & $\mathrm{x}$ & & & & & \\
\hline Surgical data & & $\mathrm{x}$ & & & & \\
\hline Patient satisfaction & & & & $\mathrm{x}$ & $\mathrm{x}$ & $\mathrm{x}$ \\
\hline Adverse events & & $\mathrm{x}$ & $\mathrm{x}$ & $\mathrm{x}$ & $\mathrm{x}$ & $\mathrm{x}$ \\
\hline
\end{tabular}

MRI magnetic resonance imaging

Tertiary outcomes included changes from baseline at 12 and 24 months post-surgery in ODI, leg pain intensity (VAS), back and leg pain frequency [VAS; $0 \mathrm{~cm}$ (pain none of the time] to $10 \mathrm{~cm}$ (pain all of the time)], and 6 and 24 month patient quality of life improvement from baseline [the Physical Component Summary (PCS) and Mental Component Summary (MCS) of the Short-Form Health Survey (SF-36) v2]. The percentage of patients attaining a minimal clinically important difference of a $\geq 4$.9-point increase in PCS [13] was calculated. Baseline and postoperative $(6,12$, and 24 months) measures of range of motion at the operated level(s), work status, pain medication, and non-drug pain treatment were also compared. Patient treatment satisfaction and adverse events (AEs) were documented up to 24 months after surgery.

All adverse findings and complications were reported regardless of severity, causation, or relatedness to the implant or surgical procedure. Relationship of AEs to surgery or device was not categorised by the investigators.

\section{Statistical analysis}

Statistical analysis was carried out for all patients implanted with a Maverick disc using the Statistical Analysis System (SAS) software package version 9.2 (SAS Institute Inc, Cary, NC, USA).

Continuous variables are described as means, standard deviations (SDs), and the $95 \%$ confidence interval (CI) of the mean. For comparisons from baseline to post-surgery, a two-sided $t$ test was applied. The normality assumption was tested by a Shapiro-Wilk test to report a two-sided
Wilcoxon signed-rank test if the normality assumption was violated. However, for all instances where the ShapiroWilk test indicated a significant deviation from normality, both the $t$ test and the Wilcoxon signed-rank test were significant with $P<0.0001$ for all comparisons reported. Statistical significance was defined as $P \leq 0.05$. As secondary analysis, the differences in mean ODI score from baseline to 6,12 , and 24 months postoperatively was analysed with a repeated measurements analysis of variance (ANOVA) model. Changes in mean VAS score for back pain intensity were analysed over time in a similar manner. Both the absolute and relative frequencies of categorical variables were calculated.

Mean SF-36 PCS and MCS scores were calculated only for patients who completed $\geq 50 \%$ of the items. For patients who completed $\geq 50 \%$ of the items but who had missing values, the average score across the completed items was calculated to estimate the missing item values. Other outcomes with missing values were calculated without inclusion of a value for the patient in question.

\section{Results}

One hundred thirty-four patients with back pain were implanted with Maverick discs and followed for 2 years with $104(78 \%)$ evaluable patients remaining at 24 months (Fig. 1). The vast majority of patients complied with in- and exclusion criteria for Maverick disc replacement (Table 2). Because of the observational study design, intended to reflect routine practice, patients with extended indications 


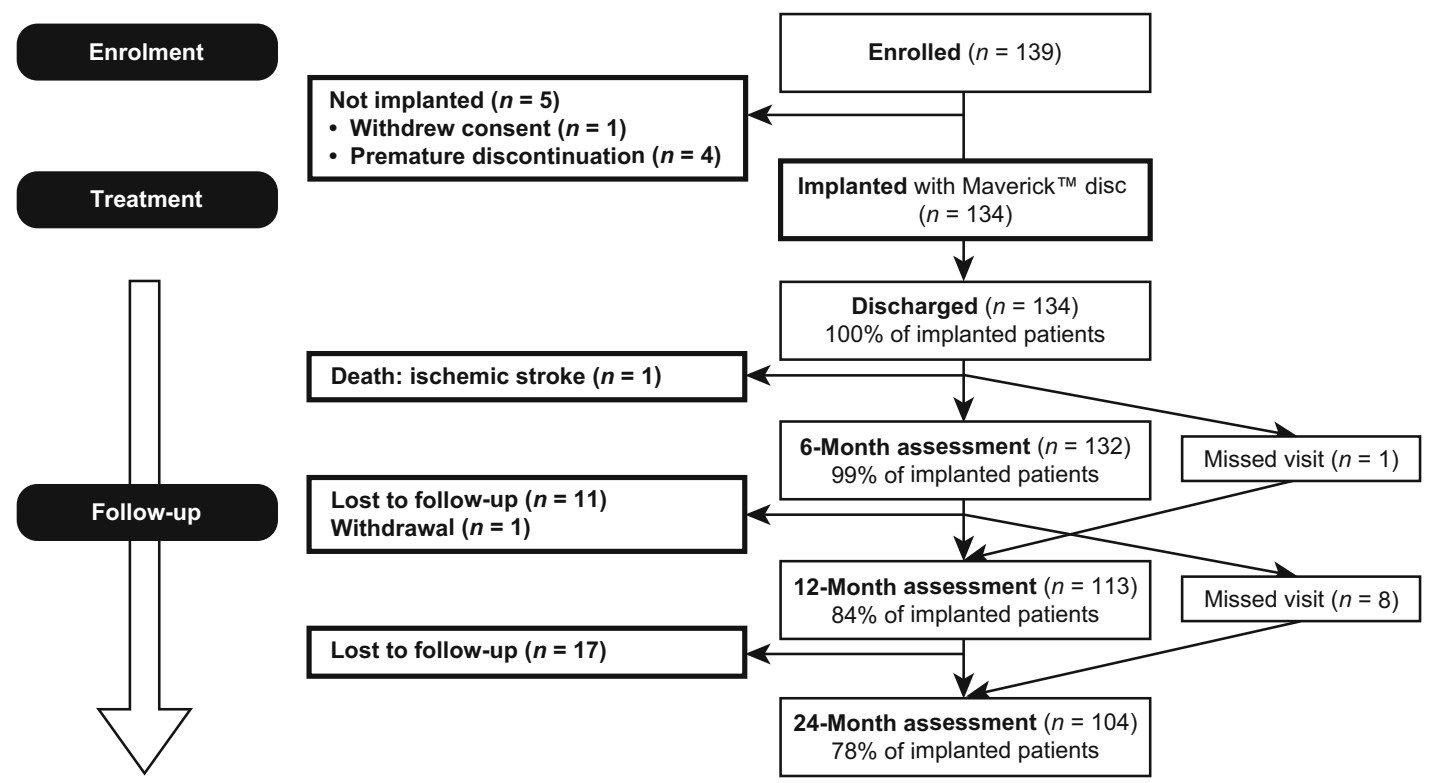

Fig. 1 Patient enrolment and follow-up. This study enrolled 139 patients. The number of patients with evaluable data from Maverick disc implantation $(n=134)$ through follow-up at 24 months $(n=104)$ is described. The bold boxes on the left describe the

Table 2 Baseline characteristics of patients implanted with a Maverick disc

\begin{tabular}{ll}
\hline Baseline characteristics & $\begin{array}{l}\text { Patients } \\
(n=134)\end{array}$ \\
\hline Male, $n(\%)$ & $64(48 \%)$ \\
Age (years) at surgery, mean years (SD; range) & $43(9 ; 22-65)$ \\
BMI $\left(\mathrm{kg} / \mathrm{m}^{2}\right)$, mean (SD) & $24.8(3.3)$ \\
Months since onset of discogenic pain, median & $15(7-33)$ \\
(Q1-Q3) & \\
Period of conservative treatment before Maverick implant, $n(\%)$ \\
0-3 months & $9(7 \%)$ \\
$3-6$ months & $19(14 \%)$ \\
6-12 months & $27(20 \%)$ \\
1-2 years & $28(21 \%)$ \\
$>2$ years & $51(38 \%)$ \\
Previous lumbar surgeries, $n(\%)$ & \\
At implanted level, $n(\%)$ & $41(31 \%)$ \\
Indications for total disc replacement & $26(19 \%)$ \\
Degenerative disc disease & $100 \%$ \\
Leg pain (VAS $\geq 2)$ & $88 \%$ \\
\hline
\end{tabular}

$S D$ standard deviation, $V A S$ visual analogue scale

were included in the analysis. The number of implants per patient, length of surgery, and blood loss observed during the study are described in Table 3. The lumbar spine was approached anteriorly through retroperitoneal exposure for patients who had no evaluable data for the subsequent evaluations, whereas the boxes on the right describe those patients who missed visits, but completed subsequent assessments

most patients $[n=131 ; 98.5 \%$; transperitoneal: $n=2$; $1.5 \%$ (approach data are missing for one patient)].

\section{Disability}

Mean (SD) ODI score was 50.1 (16.2) at baseline and 24.2 (18.5) at 6 months. Mean ODI score had reduced significantly by 25.4 points (patient with paired values: $n=122 ; 95 \%$ CI -29.0 to $-21.9 ; P<0.0001$; Fig. 2 ) and it continued to decrease through 24 months. According to FDA success criterion ( $\geq 15$-point improvement in ODI) [9], 74.6 and $75.2 \%$ of patients had successful outcomes at 6 and 24 months, respectively.

\section{Pain and pain medication}

Mean low back pain intensity scores (VAS) decreased significantly from baseline to 6 months $(-4.0 ; 95 \% \mathrm{CI}$ -4.5 to $-3.4 ; P<0.0001$ ), and further reductions were noted through 24 months (Fig. 3). Reductions in the intensity and frequency of leg pain over the same time period were also noted (Table 4).

The number of patients requiring non-drug pain interventions or pain medicine post-surgery was reduced (Table 4), as was the usage of all types of medications: nonopioids or nonsteroidal anti-inflammatory drugs, mild and strong opioids, neuropathic pain medications, and adjuvants. 
Table 3 Surgical parameters

\begin{tabular}{lclc}
\hline Number of implants & $\begin{array}{l}\text { Total patients } \\
(n=134)\end{array}$ & $\begin{array}{l}\text { Operative time } \\
(\text { min), mean (SD), } n\end{array}$ & $\begin{array}{l}\text { Blood loss (mL), } \\
\text { mean (SD), } n\end{array}$ \\
\hline One level, $n(\%)$ & $123(92 \%)$ & & \\
L3-L4 & $5(4 \%)$ & & \\
L4-L5 & $56(42 \%)$ & & $150(121), 70$ \\
L5-S1 & $62(46 \%)$ & $101(43), 77$ & $273(163), 35$ \\
One implant, no fusion & & $149(42), 40$ & \\
One implant, adjacent fusion & $10(7 \%)$ & $90(43)$ & \\
Two levels, $n(\%)$ & $2(2 \%)$ & & 510 \\
L3-L4 + L4-L5 & $1(1 \%)$ & & \\
L3-L4 + L5-S1 & $7(5 \%)$ & & \\
L4-L5 + L5-S1 & $1(1 \%)$ & 98 & \\
Three levels, $n(\%)$ & $1(1 \%)$ & & \\
L3-S1 & & & \\
\hline
\end{tabular}

$S D$ standard deviation

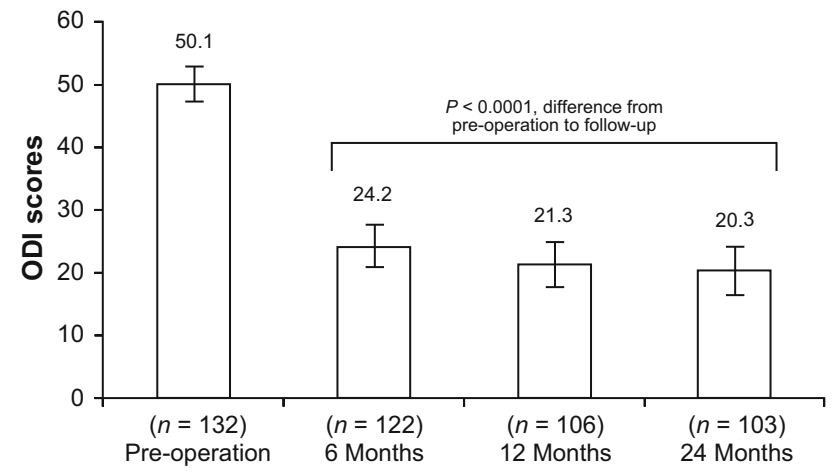

Fig. 2 Reduction in disability. Disability was measured pre-operatively and at 6,12 , and 24 months postoperatively using the Oswestry Disability Index (ODI version 2.1). Compared with preoperative mean ODI scores, all follow-up mean ODI scores were statistically significant (error bars depict the $95 \%$ confidence intervals)

\section{Range of motion}

Postoperatively, most patients with available radiographs had $\geq 3^{\circ}$ of motion (extension-flexion) at the implant level: $84 \%(53 / 63), 87 \%(52 / 60)$, and $85 \%(52 / 61)$ at 6, 12, and 24 months, respectively. By 6, 12, and 24 months, mean (SD) range of motion increased to $8.4^{\circ}(4.4 ; 95 \% \mathrm{CI}$ 7.3-9.5), 8.4 ${ }^{\circ}$ (4.9; $95 \%$ CI 7.1-9.7), and $9.4^{\circ}(5.6 ; 95 \%$ CI 8.0-10.9), respectively, from the mean pre-operative range of motion of $6.2^{\circ}(4.8 ; 95 \%$ CI 5.0-7.5).

\section{Work status}

At baseline, 58 patients (43\%) were not working, 55 of them $(95 \%)$ ascribing this to back problems. Six months

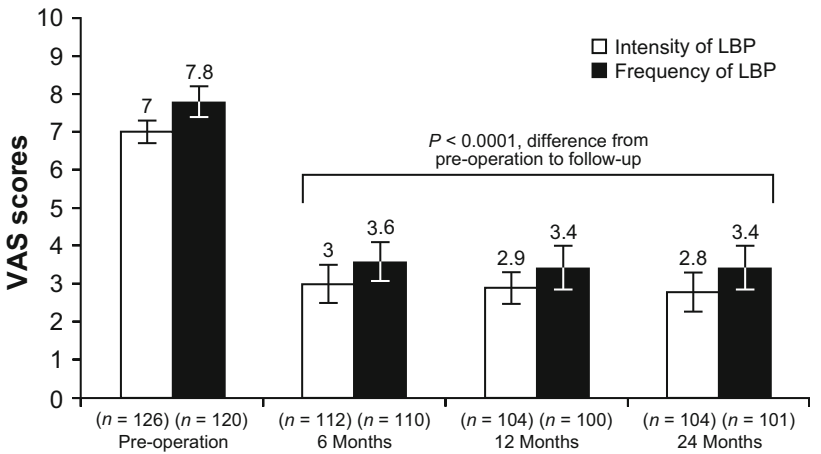

Fig. 3 Low back pain relief. Low back pain (LBP) intensity and frequency were assessed pre-operatively and at 6,12 , and 24 months postoperatively using the $10-\mathrm{cm}$ visual analogue scale [VAS; $0 \mathrm{~cm}$ (no pain) to $10 \mathrm{~cm}$ (worst possible pain)]. Compared with preoperative mean VAS scores, all follow-up mean VAS scores were statistically significant (error bars depict the $95 \%$ confidence intervals)

post-surgery, this number increased to $75(57 \%)$ but only 49 patients $(65 \%)$ ascribed this to back problems. By 12 and 24 months, these numbers had reduced below baseline to $39(37 \%)$ and $36(36 \%)$, respectively, with 20 patients citing back problems. Figure 4 shows return to work information of professional workers who had to stop working due to back problems pre-surgery.

\section{Quality of life}

Mean SF-36 PCS and MCS scores significantly increased postoperatively, with an 11.6-point and 8.8-point increase from baseline at 6 months, then to 14.4 and 9.8 at 24 months $(P<0.0001$ for all; Fig. 5). $76 \%$ of patients had a successful ( $\geq 4$.9-point increase in PCS) outcome at 24 months. 
Table 4 Changes in tertiary outcomes from pre-operation (baseline) to 2 years

\begin{tabular}{|c|c|c|c|c|}
\hline Outcome & Pre-operation & $\begin{array}{l}6 \text { months } \\
\text { post-surgery }\end{array}$ & $\begin{array}{l}12 \text { months } \\
\text { post-surgery }\end{array}$ & $\begin{array}{l}24 \text { months } \\
\text { post-surgery }\end{array}$ \\
\hline \multicolumn{5}{|l|}{ Leg pain $(\mathrm{VAS})^{\mathrm{a}}$} \\
\hline Intensity, mean (SD), total $n$ & $5.2(3.0), 125$ & $2.3(2.4), 113$ & $2.4(2.9), 103$ & $2.8(2.8), 104$ \\
\hline Frequency, mean (SD), total $n$ & $5.7(3.1), 119$ & $2.7(2.9), 111$ & $2.7(3.2), 100$ & $2.8(3.1), 101$ \\
\hline Patients taking pain medication ${ }^{\mathrm{b}}, n /$ total $(\%)$ & $115 / 133(87 \%)$ & $79 / 127(62 \%)$ & $44 / 104(42 \%)$ & $43 / 96(45 \%)$ \\
\hline Patients using non-drug pain treatments ${ }^{\mathrm{b}}, n /$ total $(\%)$ & $90 / 134(67 \%)$ & $68 / 127(54 \%)$ & $41 / 104(39 \%)$ & $32 / 95(34 \%)$ \\
\hline \multicolumn{5}{|l|}{ Patient satisfaction } \\
\hline \multicolumn{5}{|l|}{ Would the patient have the treatment again $?^{\mathrm{c}}$} \\
\hline Yes, $n /$ total $(\%)$ & & $101 / 120(84 \%)$ & 76/96 (79\%) & $77 / 94(82 \%)$ \\
\hline No, $n /$ total $(\%)$ & & $5 / 120(4 \%)$ & $7 / 96(7 \%)$ & $8 / 94(9 \%)$ \\
\hline Unsure, $n /$ total $(\%)$ & & $14 / 120(12 \%)$ & $13 / 96(14 \%)$ & $9 / 94(10 \%)$ \\
\hline \multicolumn{5}{|l|}{ Have you completely recovered ${ }^{\mathrm{d}}$} \\
\hline Improved, $n /$ total (\%) & & $117 / 122(96 \%)$ & $89 / 99(90 \%)$ & $80 / 99(81 \%)$ \\
\hline Worsened, $n /$ total (\%) & & $1 / 122(1 \%)$ & $1 / 99(1 \%)$ & $9 / 99(9 \%)$ \\
\hline No change, $n /$ total (\%) & & $4 / 122(3 \%)$ & 9/99 (9\%) & $10 / 99(10 \%)$ \\
\hline
\end{tabular}

$S D$ standard deviation, $V A S$ visual analogue score

${ }^{a}$ Improvements from pre-operative in each group were examined by paired $t$ test and shown to be highly significant $(P<0.0001)$

b Not specific to lumbar pain; non-drug pain interventions included structured physical therapy, bracing or orthoses, spinal injections or nerve blocks, and back school

c "Yes" describes those who answered either "definitely true" or "mostly true," while "no" describes those who answered "definitely false" and "mostly false"

d "Improved" describes those who answered, "completely recovered," "much improved," and "slightly improved," while "worsened" describes those who answered "vastly worsened," "much worsened," and "slightly worsened"

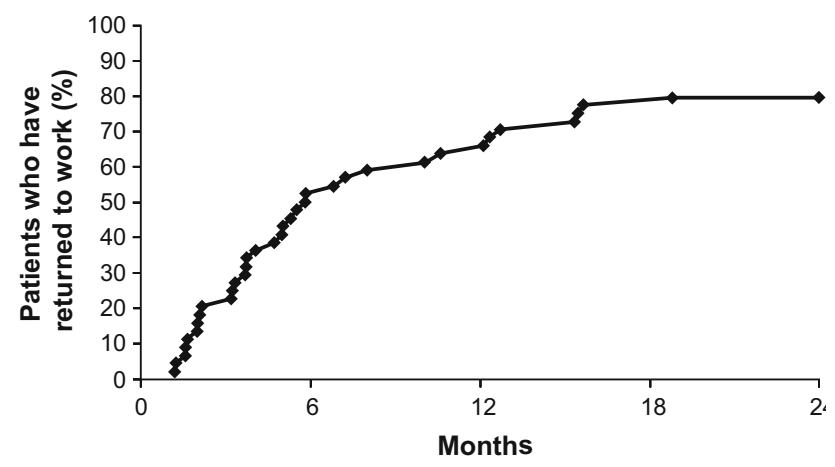

Fig. 4 Return to work. Patients' work status was assessed postoperatively through 24 months. Only professional workers who had to stop working before surgery are depicted below (not those who were retired, unemployed, a student, or a homemaker). The number of professional workers who returned to work post-surgery was divided by the total number of professional workers for which data on resuming work was available

\section{Patient satisfaction}

Patients were asked (1) whether they would have the treatment again, and (2) whether they had completely

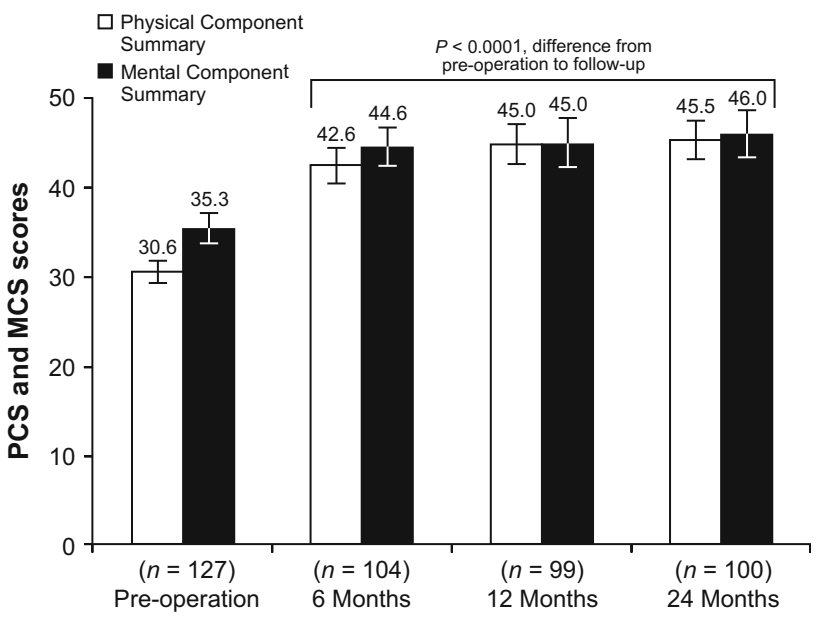

Fig. 5 Improvement in quality of life. Patient quality of life was measured pre-operatively and at 6,12 , and 24 months postoperatively using the Physical Component Summary (PCS) and Mental Component Summary (MCS) of the Short-Form Health Survey (SF-36) v2. Compared with pre-operative mean scores, all follow-up mean PCS and MCS scores were statistically significant (error bars depict the $95 \%$ confidence intervals) 
Table 5 Early adverse events (up to 6 months post-surgery)

\begin{tabular}{|c|c|c|c|c|c|}
\hline Adverse event category & $\begin{array}{l}\text { Early adverse events } \\
\text { (up to } 6 \text { months) }\end{array}$ & $\begin{array}{l}\text { Resolved } \\
\text { without delay }\end{array}$ & $\begin{array}{l}\text { Resolved } \\
\text { before study end }\end{array}$ & $\begin{array}{l}\text { Not resolved } \\
\text { at study end }\end{array}$ & Death \\
\hline Abdominal wall & 9 & 4 & 5 & & \\
\hline Neuro-hypogastric plexus injury & - & & & & \\
\hline Neuro-access-related & 13 & & 5 & 8 & \\
\hline Vascular & 3 & 3 & & & \\
\hline Visceral-bowel or peritoneum & 1 & 1 & & & \\
\hline Visceral-genito-urinary tract & 5 & 3 & 2 & & \\
\hline Misplacement & - & & & & \\
\hline Displacement & - & & & & \\
\hline Subsidence/impaction & 1 & & & $1^{\mathrm{a}}$ & \\
\hline Foreign body reaction & - & & & & \\
\hline Early nonspecific low back pain & 5 & 1 & 2 & 2 & \\
\hline Other & 9 & 6 & & 2 & $1^{\mathrm{b}}$ \\
\hline
\end{tabular}

${ }^{a}$ Specified by the investigator as completely asymptomatic radiological finding

b Death from ischaemic stroke

recovered pre-operative health: they reported an overall positive perceived effect (Table 4).

Results of other tertiary outcomes are shown in Online Resource 1.

\section{Adverse events}

Fifty seven patients $(42 \%)$ experienced a complication or AE. AEs occurring within 6 months post-surgery are described in Table 5. Between 6 and 24 months, the following additional AEs occurred (in parentheses the number of events not resolved at study end): 13 late radiculopathies (10), 6 occurrences of late nonspecific low back pain (3), and 18 other events (10). One foreign body (allergic) reaction was observed during the 2-year follow-up period. Resolution of AEs included re-operation for abdominal wall weakness or haematoma for three patients and removal of the implant for the patient with the foreign body reaction for persisting pain. Two other surgeries-one on the foot, one on the hip-were not linked to the spine pathology.

\section{Discussion}

This prospective observational study examined the effectiveness of the Maverick TDR prosthesis under real-life surgical conditions in patients receiving routine standard care for DDD at their respective centres. It is the first international study reporting outcomes of TDR in a wide patient population treated under different national standards of care. To date, limited information derived from a national registry (Switzerland) is available on outcomes following TDR in patients treated outside a controlled clinical study setting $[10,12]$. Two publications of TDR based on a national registry have reported reductions in low back pain at a mean follow-up time of 8 months [10] and 1 year [12]. Changes in disability, however, were not measured in these observational study settings.

Despite the uncontrolled nature of current study, the findings are similar to those of previous prospective randomised studies [2, 9, 14]. This registry demonstrated statistically significant improvements in its primary and secondary endpoints-disability (ODI) and back pain (VAS) scores 6 months postoperatively-which were maintained through 12- and 24-month follow-ups. Change in ODI met the criteria for a clinically important difference as defined by the FDA with $75.2 \%$ of patients having $\geq 15$ point improvement at 24 months [8]. In the randomised controlled trial (RCT) comparing Maverick disc implants versus interbody fusion, this was $82.2 \%$ of the patients [9]. Mean low back pain scores observed in both studies underwent significant reductions from pre-operation to 6 and 24 months (registry: $P<0.0001 ; \quad$ RCT: $P<0.001$ ), although a direct comparison of the results is not possible because the RCT employed a 0-100 VAS scale and this study used a 0-10 scale [9]. Like the prospective randomised studies, reductions in pain and disability were attained in the first year of this study, and lower values maintained in the second year $[2,9,14]$. Changes from preoperation to 6 and 24 months in mean ODI and VAS scores observed in this study are also comparable to other prospective studies of Maverick TDR, including the 4-year prospective study $[4,9]$. Taken together, these findings 
suggest that Maverick TDR performed in current, real-life surgical settings can provide similar outcomes to those seen in trials.

The registry population had $64 \%$ of patients that returned to work 2 years postoperatively. In the Maverick RCT, the multi-device RCT and the PRODisc prospective nonrandomised study, the percentages should be $68 \%$, $74 \%$ and $76 \%$, respectively [3, 9, 14]. Only $20 \%$ of this registry population ascribed their lack of work to back problems. The work status at 2 years in this registry was equivalent to that observed in the prospective, randomised investigational device exemption (IDE) CHARITE trial: $63 \%$ [2]. Comparisons of work status across studies conducted at different times and in different locations, however, must be tempered by the influence of the current employment rate and local practice recommendation for post-surgical work hiatus, and type of study.

Like the Maverick RCT and the Maverick 4-year prospective study, this registry noted a significant increase in the patient's quality of life from pre-surgery to 6 months and 2 years post-surgery $[4,9]$. A total of $78 \%$ of patients in the Maverick RCT reported that they had either completely recovered or were much improved after 2 years [9] compared with $81 \%$ of reported improvements in this registry. Furthermore, $82 \%$ of patients in this registry compared to $86 \%$ of patients in the PRODisc study [3] and $73 \%$ in the randomised IDE CHARITE trial reported that they would have the treatment again [2].

The incidence of AEs (42\%)-prompting reportingduring the 2-year follow-up in this observational study is lower than the rate observed in the Maverick RCT $(>80 \%)$ [9]. Overall complication rates reported in the published literature range from 1 to $40 \%$ [3]. One case of allergic reaction was noted (first symptoms at 1 year) and the prosthesis was explanted. The Maverick RCT also reported one case of metallurgic allergy at 7 months [9]. This rare problem has been previously noted and is due to the creation of ionic species at the metallic articulating surfaces precipitating a cell-mediated hypersensitivity reaction (type IV) [15, 16].

Limitations of this study are related to the nature of multicentre observational non-comparative studies. These include variations in surgical centre standards of care, assessment, follow-up, and lack of a control group. At the same time, this "real-life" setting offers insight into the effectiveness of TDR for treating DDD with high external validity.

In conclusion, this international prospective observational study shows that TDR performed by experienced surgeons, leads to a statistically significant improvement in disability (ODI) and pain (VAS) scores at 6 months, which were maintained for 2 years, providing the first evidence of the effectiveness of TDR in real-world clinical settings across countries and patient populations, with an acceptable rate of perioperative complications. The similarity in outcomes of this registry compared to those from RCTs support the use of registry data for assessing interventions.

Acknowledgments The authors wish to thank the Medtronic clinical study manager Dr. Christian Pittet for conducting the MAVERICK study; Dr. Cristina Faria (clinical affairs manager), Drs. Kirstin Demesmaeker and Alexander Cristea (medical affairs managers), Dr. Mayra Mori (scientific communications specialist) and Monica Bromley for technical review of the manuscript. The authors also thank Bert Parmet and Jacques P. G. Janssen from CromSource for performing the statistical analysis and Dr. Rebecca Bachmann Quintiles for medical writing assistance. CromSource and Quintiles were contracted as independent providers and funded by Medtronic.

Conflict of interest Medtronic grant funds were received to support the trial. Richard Assaker, Jean-Charles Le Huec, and Jörg Franke: Consultancy agreement with Medtronic. Other financial activities outside submitted work: Dominique Vardon and Jorg Franke: Medtronic honoraria for lectures. None of the authors received payment for writing the manuscript.

\section{References}

1. Le Huec JC, Mathews H, Basso Y et al (2005) Clinical results of Maverick lumbar total disc replacement: 2-year prospective follow-up. Orthop Clin North Am 36(3):315-322

2. Blumenthal S, McAfee PC, Guyer RD et al (2005) A prospective, randomized, multicenter food and drug administration investigational device exemptions study of lumbar total disc replacement with the CHARITE artificial disc versus lumbar fusion: part I: evaluation of clinical outcomes. Spine (Phila $\mathrm{Pa}$ 1976) 30(14):1565-1575

3. Siepe CJ, Mayer HM, Wiechert K, Korge A (2006) Clinical results of total lumbar disc replacement with ProDisc II: 3-year results for different indications. Spine (Phila Pa 1976) 31(17): 1923-1932

4. Van de Kelft E, Verguts L (2012) Clinical outcome of monosegmental total disc replacement for lumbar disc disease with ball-and-socket prosthesis (Maverick): prospective study with 4-year follow-up. World Neurosurg 78(3-4):355-363

5. Geisler FH, Blumenthal SL, Guyer RD et al (2004) Neurological complications of lumbar artificial disc replacement and comparison of clinical results with those related to lumbar arthrodesis in the literature: results of a multicenter, prospective, randomized investigational device exemption study of Charite intervertebral disc. Invited submission from the Joint Section Meeting on Disorders of the Spine and Peripheral Nerves, March 2004. J Neurosurg Spine 1(2):143-154

6. Huang RC, Tropiano P, Marnay T, Girardi FP, Lim MR, Cammisa FP Jr (2006) Range of motion and adjacent level degeneration after lumbar total disc replacement. Spine J 6(3):242-247

7. Ghiselli G, Wang JC, Bhatia NN, Hsu WK, Dawson EG (2004) Adjacent segment degeneration in the lumbar spine. J Bone Joint Surg Am 86-A(7):1497-1503

8. Mathews HH, Le Huec JC, Friesem T, Zdeblick T, Eisermann L (2004) Design rationale and biomechanics of Maverick total disc arthroplasty with early clinical results. Spine J 4(6 Suppl):268S275S

9. Gornet MF, Burkus JK, Dryer RF, Peloza JH (2011) Lumbar disc arthroplasty with Maverick disc versus stand-alone interbody 
fusion: a prospective, randomized, controlled, multicenter investigational device exemption trial. Spine (Phila Pa 1976) 36(25):E1600-E1611

10. Zweig T, Aghayev E, Melloh M, Dietrich D, Roder C (2012) Influence of preoperative leg pain and radiculopathy on outcomes in mono-segmental lumbar total disc replacement: results from a nationwide registry. Eur Spine J 21(Suppl 6):S729-S736

11. Chin KR (2007) Epidemiology of indications and contraindications to total disc replacement in an academic practice. Spine J 7(4):392-398

12. Aghayev E, Henning J, Munting E, Diel P, Moulin P, Roder C (2012) Comparative effectiveness research across two spine registries. Eur Spine J 21(8):1640-1647

13. Copay AG, Glassman SD, Subach BR, Berven S, Schuler TC, Carreon LY (2008) Minimum clinically important difference in lumbar spine surgery patients: a choice of methods using the Oswestry Disability Index, Medical Outcomes Study questionnaire Short Form 36, and pain scales. Spine J 8(6):968-974

14. Berg S, Tullberg T, Branth B, Olerud C, Tropp H (2009) Total disc replacement compared to lumbar fusion: a randomised controlled trial with 2-year follow-up. Eur Spine J 18(10): 1512-1519

15. Zairi F, Remacle JM, Allaoui M, Assaker R (2013) Delayed hypersensitivity reaction caused by metal-on-metal total disc replacement. J Neurosurg Spine 19(3):389-391

16. Gornet MF, Burkus JK, Harper ML, Chan FW, Skipor AK, Jacobs JJ (2013) Prospective study on serum metal levels in patients with metal-on-metal lumbar disc arthroplasty. Eur Spine J 22(4): $741-746$ 